\title{
Doenças do trabalho: africanos, enfermidades e médicos nas plantations, sudeste escravista (aproximações)
}

\author{
Occupational diseases: Africans, diseases and doctors on \\ plantations, slave south-east (preliminary notes)
}

\section{lamara da Silva Viana* Flávio dos Santos Gomes* Tânia Salgado Pimenta ${ }^{* * *}$}

\begin{abstract}
Resumo: A partir da década de 1990 se desenvolveram estudos históricos sobre doenças dos escravizados no Brasil com base em pesquisas sobre escravidão. Houve uma conexão entre estudos voltados para saúde e para escravidão, destacando-se as pesquisas sobre o pensamento médico sobre os africanos, a identificação das doenças, as práticas de cura e a assistência médica. Neste artigo analisamos as relações entre doenças e as condições de trabalho em áreas cafeeiras. Apresentando um panorama da historiografia, analisamos os impactos dos regimes de trabalho nos corpos dos trabalhadores africanos.
\end{abstract}

Palavras-chave: doenças; trabalho; escravidão; africanos; plantation.

Abstract: In the 1990s, historical studies on slave diseases in Brazil emerged based on research on slavery. New studies have examined medical thinking about Africans, the identification of diseases, healing practices and medical assistance. The article analyzes the

* Doutora em História Política pela Universidade Estadual do Rio de Janeiro (UERJ). Professora do Departamento de História da Pontifícia Universidade Católica do Rio de Janeiro (PUC-Rio). ORCID: http://orcid.org/00000002-7290-4995. E-mail: ia.sviana@gmail.com.

** Doutor em História Social pela Universidade Estadual de Campinas (Unicamp). Professor da Universidade Federal do Rio de Janeiro (UFRJ); Bolsista de Produtividade em Pesquisa do CNPq - Nível 1B. ORCID: http:// orcid.org/0000-0002-2386-7040. E-mail: escravo@prolink.com.br.

*** Doutora em História Social pela Universidade Estadual de Campinas (Unicamp). Pesquisadora do Departamento de Pesquisa em História das Ciências e da Saúde (Fiocruz); Professora do PPG em História das Ciências e da Saúde (Fiocruz). ORCID: https://orcid.org/0000-0002-9042-7133 E-mail: taniacoc@gmail.com. 
connections between diseases and working conditions in coffee areas. Based on the panorama of historiography, the impact of work regimes on the bodies of African workers is analyzed.

Keywords: diseases; work; slavery; Africans; plantation.

O S ESTUDOS HISTÓRICOS sobre doenças dos escravizados no Brasil têm se desenvolvido, sobretudo, a partir da década de 1990, com pesquisas originadas das historiografias sobre escravidão e sobre saúde. Com o tema em comum, o diálogo entre esses dois campos começou a se intensificar e a produção sobre saúde e escravidão passou a levantar questões próprias, em que se destacam a agência de escravizados, libertos e seus descendentes nascidos livres, assim como as redes de solidariedade construídas por eles. Percebe-se um adensamento de publicações a partir da década de 2010 com investigações acerca do pensamento médico sobre os africanos e seus descendentes; da identificação e distribuição das doenças que mais atingiam os cativos e libertos; e do exercício das práticas de cura por essas pessoas. ${ }^{1}$ Neste artigo analisamos as conexões entre doenças e trabalho em áreas cafeeiras. Ao apresentar o panorama da historiografia temática, localizamos as possibilidades analíticas de abordar os impactos dos regimes de trabalho nos corpos dos trabalhadores africanos.

\section{Historiografia: temas e abordagens}

DURANTE TODO O PERÍODO DA ESCRAVIDÃO, as doenças atravessaram a existência de africanos e seus descendentes devido as suas condições de trabalho e de vida. Para enfrentar as enfermidades, recorriam a práticas de cura construídas a partir de suas concepções de doença e saúde, formadas em suas experiências e relações com os diversos grupos sociais. ${ }^{2}$ Soma-se a isso, a convivência de médicos com os cativos, enquanto trabalhadores ou doentes, o que se torna mais evidente a partir da primeira metade do século XIX, quando a medicina acadêmica iniciou seu processo de institucionalização no Brasil com a criação da Sociedade de Medicina do Rio de Janeiro (1829), poucos anos depois transformada em Academia Imperial de Medicina (1835); das Escolas de Cirurgia (1808) de Salvador e do Rio de Janeiro, reorganizadas em Academias Médicas-Cirúrgicas e, em 1832, em Faculdades de Medicina; e de periódicos especializados em medicina. Essas instituições constituíram espaços sociais importantes para o trabalho de tradução local da higiene à realidade brasileira, através da qual

1 BARBOSA, Keith; GOMES, Flávio. Doenças, mortes e escravidão africana: perspectivas historiográficas. In: PIMENTA, Tânia S.; GOMES, Flávio (org.). Escravidão, doenças e práticas de cura no Brasil. Rio de Janeiro: Outras Letras, 2016. p. 273-305; PIMENTA, Tânia; GOMES, Flávio; KODAMA, Kaori. Das enfermidades cativas: para uma história da saúde e das doenças do Brasil escravista. In: TEIXEIRA, Luiz Antonio; PIMENTA, Tânia; HOCHMAN, Gilberto (org.). História da saúde no Brasil. São Paulo: Hucitec Editora, 2018. p. 67-100.

2 Reconhecemos a importância da produção historiográfica sobre o tema voltada para o século XVIII, mas o recorte dessa análise se limita aos estudos sobre o século XIX em função das questões apresentadas no texto. 
se pretendia identificar e relacionar as doenças que se desenvolviam no país, sobretudo, ao clima e à alimentação. Além disso, as faculdades contribuíram para o aumento quantitativo de médicos ao menos nos centros urbanos maiores. ${ }^{3}$

Os médicos desse tempo não podiam deixar de perceber e conviver com as pessoas escravizadas que circulavam e desempenhavam todo tipo de trabalho. Nesse mesmo período da primeira metade do Oitocentos, desembarcaram no Brasil quase dois milhões de africanos escravizados. ${ }^{4}$ Muitos deles chegaram à baía da Guanabara e continuaram viagem em direção a outras províncias. Outros tantos ficaram no Rio de Janeiro, que, em 1849, era a cidade das Américas com o maior número de escravos, onde viviam e trabalhavam 80.000 cativos. ${ }^{5}$ O Rio de Janeiro, como capital e sede de importantes instituições médicas, concentrava também o maior número de médicos.

Assim, africanos e seus descendentes, na condição de escravizados, libertos ou livres, foram observados, examinados e tratados por estudantes e professores de medicina no hospital da Santa Casa da Misericórdia, onde se davam as aulas práticas da Faculdade de Medicina do Rio de Janeiro, e por médicos dessa instituição e em suas clínicas particulares. Desse modo, diversas teses de conclusão de curso referiam-se, como tema central ou não, às doenças que atingiam esse grupo ou aos tratamentos aos quais foram submetidos. Embora os registros de entrada e saída de doentes do hospital da Misericórdia carioca não tenham sido localizados, relatórios e artigos de médicos publicados nos periódicos especializados fornecem alguns dados que permitem um desenho um pouco mais nítido sobre a população tratada lá. Alguns médicos escreveram também sobre a administração da mão de obra escrava em fazendas, atentando para as condições de moradia, vestimenta, alimentação e saúde, baseados em suas experiências. Além disso, processos de cobrança de dívida e inventários post mortem de senhores de escravos e de médicos contêm, com frequência, informações sobre o estado de saúde e o tratamento de escravizados. Literalmente, por fim, os próprios óbitos, indicando as causas mortis, eram registrados nos assentos eclesiásticos, documentos dos cemitérios ou nos atestados passados pelos médicos.

Os historiadores interessados em conhecer melhor as condições das pessoas que tiveram suas vidas atravessadas pela experiência da escravidão têm recorrido a esse leque de fontes, que vem sendo ampliado. Nesse sentido, o trabalho pioneiro de Mary Karasch sobre a vida dos escravos no Rio de Janeiro na primeira metade do século XIX se destaca pela diversidade e volume de fontes analisadas. Ainda que desenvolva um capítulo sobre as doenças que mais levaram os escravizados à morte, ao longo de todo o livro a autora mostra

3 Ver: FERREIRA, Luiz Otávio. O nascimento de uma instituição científica: os periódicos médicos brasileiros da primeira metade do século XIX. 1996. Tese (Doutorado em História) - Faculdade de Filosofia, Letras e Ciências Humanas, Universidade de São Paulo, São Paulo, 1996; FERREIRA, Luiz Otávio. Introdução: José Francisco Xavier Sigaud e a tradução local do higienismo. In: SIGAUD, J.F.X. Do clima e das doenças do Brasil ou estatística médica deste Império. Rio de Janeiro: Fiocruz, 2009 [1844]. p. 17-26.

4 Slave Voyages Database. Disponível em: https://www.slavevoyages.org. Acesso em:19/06/2020.

5 KARASCH, Mary. A vida dos escravos no Rio de Janeiro (1808-1850). São Paulo: Companhia das Letras, 2000. p. 28. 
que o descaso com moradia, vestimenta, alimentação e assistência concorria bastante para a alta mortalidade dessa população, sobretudo dos africanos recém-chegados, assim como o excesso e o tipo de trabalho, tornando-os mais vulneráveis às doenças. ${ }^{6}$

As consequências desse descaso acabavam sendo bastante visíveis em épocas de epidemia. Em 1855, quando o cólera se disseminou por várias províncias como "moléstia reinante", os escravizados foram os mais atingidos. Atividades de lavar roupas, cozinhar, transportar dejetos os tornavam mais vulneráveis a uma doença que se alastrava através da água e alimentos contaminados num contexto em que as condições de vida dessas pessoas, sobretudo dos libertos, eram piores do que às dos senhores em geral. Os médicos contemporâneos debatiam muito sobre o cólera se propagar por meio do contágio (entre pessoas ou objetos contaminados por pessoas) ou de infecção (por miasmas desenvolvidos a partir da decomposição de matérias orgânicas). O fato é que tanto médicos quanto africanos e seus descendentes percebiam que esses últimos eram as maiores vítimas da epidemia. Essa situação era evidente na Bahia, Pará, Pernambuco e Rio de Janeiro, conforme os primeiros estudos sobre o assunto demonstraram, chamando atenção para a relação entre as condições ruins de vida desse grupo e a incidência de determinadas doenças. ${ }^{7}$ Os africanos, especificamente, foram os que mais morreram durante a epidemia de cólera de meados do século XIX no Rio de Janeiro, de acordo com um estudo mais detido sobre o tema. ${ }^{8}$

A população africana também havia sido colocada no centro das discussões com a eclosão da epidemia de febre amarela no verão de 1849/1850. Mais especificamente, o tráfico atlântico de escravos foi posto em destaque nos debates sobre o modo como a doença teria sido importada. Assim, alguns historiadores argumentam que essa associação entre o tráfico e a febre amarela pode ter constituído mais um argumento para a cessação do primeiro, o que ocorreu pela Lei Eusébio de Queirós, de 4 de setembro de $1850 .^{9}$

$\mathrm{Na}$ verdade, não era raro que alguns esculápios estabelecessem correspondências entre a chegada de navios negreiros e a eclosão de surtos e epidemias de outras doenças também. Um dos fundadores da Sociedade de Medicina do Rio de Janeiro e editor de alguns periódicos especializados, como O Propagador das Ciências Médicas e o Diário de

$6 \quad$ KARASCH, Mary. op. cit. O livro em inglês foi publicado em 1987.

7 DAVID, Onildo. O inimigo invisível, epidemia na Bahia no século XIX. Salvador: Edufba-Sarah Letras, 1996; BELTRÃO, Jane. Cólera, o flagelo da Belém do Grão-Pará. Belém: Goeldi Editoração-Editora Universitária UFPA, 2004; DINIZ, Ariosvaldo. As artes de curar no tempo do cólera, Recife, 1856. In: CHALHOUB et al. Artes e ofícios de curar no Brasil. Campinas: Editora da Unicamp, 2003. p. 355-385; FARIAS, Rosilene G. Pai Manoel, o curandeiro africano, e a medicina no Pernambuco imperial. História, Ciências, Saúde Manguinhos, v. 19, supl., pp. 215-31, 2012; PIMENTA, Tânia S. O exercício das artes de curar no Rio de Janeiro (1828-1855). Tese (Doutorado em História) - Instituto de Filosofia e Ciências Humanas, Universidade Estadual de Campinas, Campinas, 2003.

8 KODAMA, Kaori; PIMENTA, Tânia S.; BASTOS, Francisco I.; BELLIDO, Jaime G. Mortalidade escrava durante a epidemia de cólera no Rio de Janeiro (1855-1856): uma análise preliminar. História, Ciências, Saúde Manguinhos, Rio de Janeiro, v. 19, supl., p. 59-79, dez. 2012.

9 CHALHOUB, Sidney. Cidade febril: cortiços e epidemias na Corte imperial. São Paulo: Companhia das Letras, 1996. p. 73; KODAMA, Kaori. Os debates pelo fim do tráfico no periódico O Philantropo (1849-1852) e a formação do povo: doenças, raça e escravidão. Revista Brasileira de História, São Paulo, v. 28, n. 56, pp. 407-30, 2008. 
Saúde, José Francisco Xavier Sigaud (1796-1856), ${ }^{10}$ apontava a lepra, a oftalmia e a bouba como doenças trazidas pelos africanos. No entanto, assinalava também que muitas outras haviam chegado através dos europeus ou já existiam aqui. Em sua concepção higienista, que descendia do neo-hipocratismo, o clima local e o regime alimentar eram os principais aspectos para o entendimento da patologia individual e coletiva. ${ }^{11}$

Sigaud também se referiu ao maculo ${ }^{12}$ como "doença dos negros", apontando que os indivíduos procedentes de Angola e de Moçambique eram os mais atingidos e que a doença só era identificada entre os escravos recém-chegados. Ele denunciava que o tráfico "estabeleceu a troca de doenças mortíferas entre os dois continentes", destacando que

os negros, ao chegar, submetidos a um novo modo de alimentação, à influência de um clima estranho para eles, descuidados das regras de higiene, levados ao excesso ou condenados a trabalhos múltiplos, sofreram grandes alterações em sua constituição física, e daí se engendraram os elementos de doenças que lhes são particulares, verdadeiros atributos da raça negra. ${ }^{13}$

Karasch afirma que o maculo raramente foi apontado como causa de morte entre os registros de óbitos no cemitério da Santa Casa do Rio de Janeiro, mas pontua que talvez os médicos o registrassem como disenteria ou febres pútridas. ${ }^{14}$ Provavelmente a visão de que maculo fosse uma enfermidade vinculada à escravidão e à sua dimensão africana tivesse uma contrapartida atlântica, pois aparece indicado nos registros paroquiais da freguesia de Nossa Senhora dos Remédios de Luanda.

Além de atentarem para as doenças que teriam sido trazidas pelo tráfico, os médicos observavam as diversas moléstias às quais africanos e seus descendentes estavam sujeitos por suas condições de vida. O dr. José Martins da Cruz Jobim, por exemplo, a partir de sua experiência como professor da Faculdade de Medicina da Corte e como médico da Santa Casa, onde eram ministradas as aulas práticas de medicina, elaborou o Discurso sobre as moléstias que mais afligem a classe pobre do Rio de Janeiro. Tuberculose e opilação apareciam como as que mais atingiam essa população, composta em grande parte por escravizados e libertos. Sífilis, bouba e bexiga também eram bastante observadas entre os pobres em geral, mas afecções gástricas, verminoses e tétano eram doenças identificadas como mais específicas de africanos e seus descendentes escravizados ou não. Silvio Lima analisa o discurso de Cruz Jobim, evidenciando a importância do corpo de africanos e seus descendentes para o processo de construção do saber médico, através de autópsias,

10 Joseph François Xavier Sigaud, médico francês que atuou no Rio de Janeiro de 1825 a 1856, usava o nome aportuguesado em suas publicações. Publicou Do clima e das doenças do Brasil, 1844.

11 FERREIRA, op. cit., 2009, p. 25.

12 Segundo Chernoviz, maculo era uma "dilatação considerável do ânus, precedida e acompanhada de diarreia mais ou menos abundante". As causas seriam as mesmas que produziriam a diarreia e a disenteria: "aglomeração de grande número de pessoas [...] o uso de águas de má qualidade, as afecções morais tristes, o escorbuto [...]". CHERNOVIZ, Pedro. Diccionario de medicina popular e das sciencias accessorias para uso das famílias. Paris: A. Roger \& F. Chernoviz, 1890 [1842].

13 SIGAUD, op. cit., p. 119.

14 KARASCH, op. cit., p. 214. 
da observação do desenvolvimento de doenças e da realização de testes com novos medicamentos ou dosagens diferentes. ${ }^{15}$

No que tange ao mundo rural, a administração da mão de obra escrava foi modificada ao se perseguir, no início do século XIX, uma maior eficiência da agricultura brasileira. Para tanto, foi necessária a elaboração de reflexões sobre administração dos escravos, materializada em manuais agrícolas que circularam entre os proprietários rurais escravistas, em que o tratamento das enfermidades era um ponto importante, conforme mostra Rafael Marquese. ${ }^{16}$

Allison Eugenio, lamara Viana, Júlio César Pereira e Keith Barbosa aprofundam a análise acerca das observações sobre as doenças e o tratamento dado aos escravizados nas grandes fazendas e conselhos médicos para a preservação dessa força de trabalho. Outro aspecto explorado refere-se à identificação, nos relatos de médicos, das enfermidades sofridas pelos trabalhadores escravos. ${ }^{17}$ Algumas dessas pesquisas aprofundaram o estudo sobre as doenças, recorrendo ao cruzamento com outras fontes como inventários post mortem, registros de óbitos e livros de internamento de hospitais.

Desse modo, o quadro nosológico dessa população tem sido preenchido por informações de diversos contextos da escravidão no Brasil, o que contribui para a compreensão sobre as condições de vida dessas pessoas. Na cidade do Rio de Janeiro, Karasch apresenta como as principais causas de mortes de escravizados, na primeira metade do século XIX, as doenças agrupadas no rol das moléstias infectoparasíticas, em que constam tuberculose, varíola, tétano, febres intermitentes e perniciosas, febre amarela, tifo, sarampo, escarlatina, oftalmia, sarna, erisipela branca, elefantíase, sífilis, entre outras. Para Salvador, no mesmo período, os cativos atendidos no hospital da Misericórdia sofriam de doenças infectoparasíticas, ou seja, a tuberculose, a bexiga e a sífilis. Ao pesquisar os registros do mesmo hospital soteropolitano, em período posterior e com foco nos africanos, Gabriela Sampaio aponta decrepitude, tuberculose e anemia como as enfermidades mais registradas entre esse grupo. Em Aracaju, na segunda metade do Oitocentos, as doenças infectoparasíticas também constavam entre as principais causas de morte dos escravizados, conforme Bárbara Barbosa. Em Pelotas, região de charqueadas, na segunda metade do século XIX, os escravizados eram acometidos, principalmente, por tuberculose, febre tifoide,

15 LIMA, Silvio Cezar de Souza. Cruz Jobim e as doenças da classe pobre: o corpo escravo e a produção do conhecimento médico na primeira metade do século XIX. Almanack, Guarulhos, n. 22, p. 250-278, ago. 2019. p. 254 e 276.

16 MARQUESE, Rafael. Feitores do corpo, missionários da mente. Senhores, letrados e o controle dos escravos nas Américas, 1660-1860. São Paulo: Companhia das Letras, 2004.

17 EUGÊNIO, Allison. Lágrimas de sangue - a saúde dos escravos no Brasil na época de Palmares à Abolição. São Paulo: Alameda, 2016; VIANA, lamara da Silva. Doenças de escravizados em Vassouras, 1840-1880: principais causas mortis e suas implicações. In: PIMENTA; GOMES (org.), op. cit., p. 130-149; VIANA, lamara da Silva. Corpo escravizado e discurso médico: para além da anatomia (1830-1850). Revista de História Comparada, Rio de Janeiro, v. 12, n. 1, p. 172-202, 2018; PEREIRA, Júlio César M. da S. AAmérica devora os pretos: teses médicas, manuais de fazendeiros e grandes escravarias. In: PIMENTA; GOMES (org.), op. cit., p. 114-129; BARBOSA, Keith. Escravidão e saúde nas fazendas cafeeiras do Vale do Paraíba fluminense, século XIX. Revista da ABPN, Uberlândia, v. 6, n. 14, jul.-out. 2014, p. 25-49; BARBOSA, Keith. Escravos, senhores e médicos nas fazendas de Cantagalo. In: PIMENTA, Tânia Salgado; GOMES, Flávio (org.). Escravidão, doenças e práticas de cura no Brasil. Rio de Janeiro: Outras Letras, 2016. p. 90-113. 
varíola, disenteria e boubas. Em Porto Alegre, no mesmo período, faleciam, principalmente, de doenças como tuberculose, varíola, disenteria, hidropisia, diarreia, constipação. Na Illha de Santa Catarina, no entanto, a tuberculose não aparecia com frequência entre os internados no hospital, mas havia doentes de boubas, bexiga, disenteria, sífilis no início da segunda metade do Oitocentos. ${ }^{18}$

Com esses estudos, destaca-se a importância da problematização da fonte, pois é necessário atentar para as diferenças entre as documentações utilizadas, uma vez que o médico que preenchia o formulário de acompanhamento de um cativo internado em hospital talvez não tivesse o mesmo cuidado ao indicar a causa mortis no registro de óbito. Um avaliador de bens de um inventário, por sua vez, teria intenções bem diferentes das do médico ao apontar doenças ou deficiências de um escravizado. ${ }^{19}$ Assim, vale apontar também que essas fontes mostram experiências diferentes. Enquanto algumas fontes indicam doenças que levavam à morte, outras possibilitam identificar moléstias que causavam sofrimento e deixavam escravizados incapacitados para o trabalho por algum período. Outro tipo de documentação pode tratar ainda daquelas enfermidades ou condições físicas que anulavam ou limitavam a capacidade de trabalho.

Outro aspecto a ser considerado diz respeito à dificuldade para classificar as doenças em infectoparasíticas, dos sistemas digestivo, respiratório, nervoso, circulatório e geniturinário, doenças reumáticas e nutricionais, da primeira infância, de morte violenta ou acidental, gravidez e parto, o que poderia informar sobre as condições de vida e de trabalho de escravizados. Embora, em meados do século XIX, o hospital da Santa Casa da Misericórdia do Rio de Janeiro tivesse estabelecido uma lista de doenças que deveriam ser usadas pelos médicos, com o objetivo de uniformizar os diagnósticos, na prática, essa nosologia ainda demorou em ser seguida dentro e fora do hospital. Além disso, a própria concepção sobre doença oitocentista torna mais complicada a classificação das enfermidades ao indicar, muitas vezes, o que consideramos sintoma, como febre, por exemplo, como sendo a doença em si. Certamente, quando as anotações eram feitas por um leigo, a imprecisão em relação aos critérios atuais aumenta bastante.

18 KARASCH, op. cit.; BARRETO, Maria Renilda N.; PIMENTA, Tânia Salgado. A saúde dos escravos na Bahia oitocentista através do Hospital da Misericórdia. Revista Territórios \& Fronteiras, Cuiabá, v. 6, n. 2, jul.-dez., 2013; SAMPAIO, Gabriela dos R. Decrépitos, anêmicos, tuberculosos: africanos na Santa Casa de Misericórdia da Bahia (1867-1872). Almanack, Guarulhos, n. 22, p. 207-249, ago. 2019; SANTOS, Bárbara B. Moléstias do corpo escravo: doenças e morbidade entre cativos em Sergipe (1865- 1888). 2020. Dissertação (Mestrado em História) - Universidade Federal de Sergipe, Aracaju, 2020; MOREIRA, Paulo R. S. Cólera, bexiga, disenteria: epidemias e morte entre a população escrava e a formação social escravista meridional (Porto Alegre). In: FRANCO, Sebastião; PIMENTA, Tânia Salgado; MOTA, André (org.). No rastro das províncias - as epidemias no Brasil oitocentista. Vitória: EDUFES, 2019. p. 353-391; LONER, Beatriz; GILL, Lorena; SCHEER, Micaele. Enfermidade e morte: os escravos na cidade de Pelotas, 1870-1880. História, Ciências, Saúde - Manguinhos, Rio de Janeiro, v. 19, supl., p. 133-152, dez. 2012; MATTOS, Débora M. Do que eles padeciam. Doenças e escravidão na llha de Santa Catarina (1850-1859). In: PIMENTA; GOMES (org.), op. cit., p. 63-89.

19 OLIVEIRA, Daniel. Os facultativos são obrigados a declarar [...] cor, [...] moléstia: mortalidade, atuação médica e pensamento racial em Porto Alegre, na segunda metade do século XIX. 2018. Tese (Doutorado em História) - Universidade Federal do Rio Grande do Sul, Porto Alegre, 2018. 
lamara da Silva Viana, Flávio dos Santos Gomes e Tânia Salgado Pimenta

Apesar das dificuldades, o levantamento serial referente a diversos contextos pode contribuir para identificarmos mudanças temporais e espaciais na percepção das enfermidades, em suas terminologias, que consideravam a experiência escrava, condições de vida, cotidiano, suas dimensões senhoriais, africanas, crioulas e atlânticas. Desse modo, as pesquisas sobre doenças de escravizados nos ajudam a compreender melhor as diferentes experiências na escravidão.

\section{Africanos na plantation cafeeira}

ABORDAGENS SOBRE OS PADRÕES de mortalidade escrava se concentraram nos períodos do tráfico ou naqueles de quarentena pós viagens quando os índices eram altíssimos. ${ }^{20} \mathrm{Em}$ estudos clássicos, Miller argumentou que até $40 \%$ de africanos morriam, considerando as várias etapas do tráfico, passando dos sertões africanos até chegarem aos principais portos de embarque. Consta que 10 a $12 \%$ dos africanos faleciam no litoral antes de embarcarem. No período chamado de "aclimatação", ou seja, nos primeiros quatro anos de vida no Brasil, cerca da metade dos africanos morria. ${ }^{21}$

Ainda sabemos pouco sobre esses primeiros períodos da imediata chegada dos africanos ao litoral brasileiro e seu envio para as áreas produtivas. No Rio de Janeiro oitocentista, tanto podiam cumprir breve período de quarentena como podiam ser imediatamente vendidos, enviados para o interior, onde alguns fazendeiros já esperavam ávidos por suas encomendas. Para as áreas cafeeiras fluminenses, seguiam a pé em grupos, junto aos tropeiros, que contornavam serras da região, alcançando várias partes do Vale do Paraíba. ${ }^{22}$

Em Vassouras, com a expansão cafeeira e a crescente importação de africanos na primeira metade do século XIX, grandes fazendeiros adquiriam expressiva quantidade de cativos a cada ano. ${ }^{23}$ Começaria outra fase de adaptação - física e mental - nas fazendas de café. Cabe destacar que as primeiras gerações de africanos tiveram que arrumar esses cenários, quando em Vassouras, Valença, Piraí e outras áreas tiveram que desmatar a floresta atlântica, erguer fazendas, construir edifícios e depois plantar os primeiros pés de café. Análises sobre essas primeiras gerações em tais períodos de construção de cenários nem sempre foram destacadas nos estudos sobre a plantation cafeeira. ${ }^{24}$ Posteriores gerações de cativos chegaram e ali encontraram cenários econômicos montados com milhares de pés de café, senzalas, casa-grande e roças. Não foi um tempo de menos opressão, pois vivenciaram

20 ENGERMAN, Stanley L.; HAINES, Robin; KLEIN, Hebert; SHLOMOWITZ, Ralph. Transoceanic Mortality: The Slave Trade in Comparative Perspective. The William and Mary Quarterly, 3rd ser., v. 58, n. 1, pp. 93118, 2001.

21 MILLER, Joseph. Mortality in the Atlantic Slave Trade: Statistical Evidence on Causality. Journal of Interdisciplinary History, v. 11, n. 3, pp. 413-414, 1981

22 KARASCH, Mary. op. cit., cap. 2.

23 SALLES, Ricardo. E o vale era o escravo. Vassouras - século XIX. Senhores e escravos no Coração do Império. Rio de Janeiro: Civilização Brasileira, 2008.

24 SALLES, Ricardo; MUAZE, Mariana (org.). O Vale do Paraíba e o Império do Brasil nos quadros da segunda escravidão. Rio de Janeiro: 7 Letras, 2015. 
jornadas extenuantes trabalho, além de terem que organizar os espaços materiais e imateriais de uma vida escrava nova para muitos dos africanos. A maior parte dos cativos em Vassouras, ao que se sabe, deve ter habitado senzalas coletivas, talvez divididas entre homens e mulheres solteiros, sendo que os escravos casados, muitas vezes, residiam em pequenas senzalas separadas. A partir de relatos de viajantes (muitos dos quais visitaram a região do Vale do Paraíba no século XIX), Slenes analisou a construção das senzalas. ${ }^{25}$

A partir de relatos de ex-escravos e de seus descendentes, Stein reconstituiu a rotina diária de trabalho nas grandes fazendas cafeeiras em Vassouras em meados do século XIX. ${ }^{26} \mathrm{Em}$ grandes fazendas, com centenas de cativos, o início do dia de trabalho podia ser anunciado por um sino que soava forte e estridente por todo o terreiro. Algumas escravas com ocupação de cozinheiras acordavam mais cedo, preparando a alimentação matinal, que invariavelmente consistia num café fraco, rapadura e angu.

Sabemos pouco sobre essas ambiências de trabalho e menos ainda sobre a sua atmosfera de relações de trabalho, incluindo os acidentes, lesões e enfermidades geradas em gerações e gerações de cativos.

Para refletir sobre as condições de trabalho e morbidades incapacitantes dos escravizados africanos vamos utilizar algumas amostras de registros de enfermidades e condições de saúde. A nossa base de comparação para analisar os padrões de doenças e morbidade escrava no Vale do Paraíba serão os inventários post mortem para as regiões de Valença, Paraíba do Sul e Piraí. Trata-se de fontes de natureza diferente dos registros eclesiásticos de óbitos, pois não estamos mais diante de párocos (ou informações médicas traduzidas) e seus repetitivos - após os respectivos rituais - registros. Pessoas aquinhoadas e mesmo outras mais modestas ao morrerem tinham os seus bens descritos sob o acompanhamento de inventariantes e herdeiros. Fontes providenciais para estudos demográficos, padrões de posse e família escrava, inventários post mortem também revelam sobre as condições de trabalho e morbidades associadas. Bens só eram relacionados após a morte de alguém e depois avaliados para futuras partilhas entre herdeiros. Não poucos inventários ficaram abertos por anos, e outros, décadas. Disputas familiares e querelas judiciais se apresentavam. E com isso os bens assegurados.

Numa sociedade escravista, bens - entre outras coisas - representavam escravos. Eles tinham que ser suficientemente avaliados e descritos segundo as suas habilidades, aptidões, defeitos, doenças, ofícios, relações familiares. Tudo acompanhado do seu nome, sua origem - africano ou crioulo - e idade. Sabemos pouco sobre esse processo, quase invisível. Cativos sabiam da morte de seus senhores, tinham expectativa de novos donos, no caso um dos herdeiros e, provavelmente, identificavam a natureza da ação dos avaliadores.

25 Ver: SLENES, Robert. Da senzala uma flor: esperanças e recordações na formação da família escrava. Rio de Janeiro: Nova Fronteira, 1999.

26 STEIN, Stanley. Vassouras. Um município brasileiro do café, 1850-1900. Rio de Janeiro: Nova Fronteira, 1990. pp. 50-52 e 197-201. 
Mas, quem eram esses avaliadores? Certamente também proprietários de escravos, conhecedores da sociedade escravista, quiçá da natureza dos escravos. Alguém que saberia anotar (e a importância de tal anotação) - de forma precisa - as características de cada escravo e o mais importante, seus valores. Embora invisível, podemos especular sobre tal processo de avaliação. Todos os avaliadores viam cada escravo um a um e anotavam as suas características? Pouco provável. Este seria mais um processo que contaria com várias traduções: herdeiros, inventariantes, dos proprietários falecidos, parentes, feitores, vizinhos e mesmo os próprios escravos podiam contribuir com informações. Uma coisa era um avaliador visitar uma residência, sítio ou fazenda anotando bens e suas características; outra coisa era verificar um a um cada escravo, muitos dos quais trabalhando e mesmo distantes da presença do senhor.

O fato é que informações eram produzidas, acessadas e circuladas; o suficiente para que aparecessem em listagens de bens com valores individualizados. Através delas se saberia que tal escravo era crioulo ou africano, sua nação era a tal, com determinada idade, respectiva ocupação, com parentesco e valor. Presentes, próximos, invisíveis, distantes ou ausentes todos os escravos tinham que ser avaliados individualmente. Sendo uma fonte de natureza econômica estava em jogo também avaliação (desqualificação) de cativos associados a doenças incapacitantes: aleijados ou portadores de deficiências físicas crônicas ou definitivas. Inicialmente, estamos interessados numa reflexão a respeito da produção destas fontes listagens de escravos, enquanto bens arrolados em inventários post mortem - visto que nelas aparecem diferentes perfis de escravos e africanos. Detalhe: sabemos que nos registros de batizados de adultos, africanos se tratavam de recém-chegados, comprados e adquiridos. $\mathrm{O}$ mais importante a destacar é que nas listagens de inventários post mortem - considerando a variável período de aquisição de escravos novos, de morte do senhor, arrolamento e descrição de bens e abertura dos inventários, visando partilhas - podiam aparecer tanto africanos recém-chegados, há pouco comprados, como aqueles com mais de duas décadas de experiência no cativeiro e na diáspora. Azar dos senhores, posto que falecidos, nem sempre significava sorte para os cativos arrolados nos bens e muito menos sucesso para os historiadores que utilizaram essas fontes. Era comum arrolar idades, mas como saber o que elas representavam em termos de longevidade ou não de cativeiro para os variados perfis de africanos no Rio de Janeiro oitocentista?

Começamos com a mais distante plantation cafeeira do Vale do Paraíba: Valença. Consideramos uma amostra de 706 inventários entre os anos de 1830 a 1887, mas optamos por analisar o período de 1830 a 1860, com 245 inventários que contemplavam 6.421 cativos para os quais escolhemos 3.265 africanos. Ali há indicações de 220 indivíduos (6,8\%) com doenças que foram anotadas para (des)valorizar preços e avaliações. 
Tabela 1 - Morbidades que aparecem em africanos, 1830-1860, Valença

\begin{tabular}{|l|c|c|c|}
\hline "Zambo das pernas"/Pés tortos & 8 & Paralítico/Entrevado & 3 \\
\hline Surdo & 4 & Cego & 5 \\
\hline Rendido & 22 & Reumatismo & 11 \\
\hline "Quebrado" & 44 & Feridas & 9 \\
\hline "Doente"/“Adoentado" & 55 & Defeituoso & 14 \\
\hline "Aleijado" & 23 & "Com boubas" & 5 \\
\hline Aleijado da mão & 6 & Febres & 3 \\
\hline Aleijado do braço & 8 & "Tem mal de gota" & 3 \\
\hline Aleijado da perna & 9 & Morfético & 3 \\
\hline
\end{tabular}

Fonte: Arquivo do Judiciário do Tribunal de Justiça do Rio de Janeiro, inventários post mortem.

Cerca de $60 \%$ cativos africanos apresentam enfermidades incapacitantes temporárias ou definitivas. Para o município de Paraíba do Sul, nossa amostra alcança 715 inventários entre 1821 a 1887, sendo que escolhemos o período de 1825 a 1860 com 287 inventários reunindo 6.297 cativos, dos quais 2.764 africanos. Ali são registrados 261 africanos associados a doenças, sendo $65 \%$ com doenças associadas às condições incapacitantes.

Tabela 2 - Morbidades que aparecem em africanos, 1825-1860, Paraíba do Sul

\begin{tabular}{|l|c|c|c|}
\hline "Quebrado" & 49 & Defeituoso (pés, mãos e braços) & 29 \\
\hline Rendido & 32 & "Pernas tortas/inchadas" & 23 \\
\hline Opilado & 14 & Aleijado & 37 \\
\hline "Doente"/“Adoentado" & 72 & Cego & 5 \\
\hline
\end{tabular}

Fonte: Arquivo do Judiciário do Tribunal de Justiça do Rio de Janeiro, inventários post mortem.

Para o município de Piraí, nossa amostra de 1829 a 1887 enquadra 251 inventários, sendo que optamos por analisar o período de 1830 a 1860, com 126 inventários, 5.488 cativos, sendo 2.898 africanos. Destes, temos 157 registros de doenças, sendo as indicações mais concentradas "quebrado" (34), "rendido" (15), "doente" (19), "defeituoso" (9) e "aleijado" (23), quais sejam associadas às condições e morbidades relativas às atividades do trabalho. 
Tabela 3 - Enfermidades escravas: registros paroquiais de óbitos e inventários post mortem, Vassouras, 1840-1880

\begin{tabular}{|l|c|c|c|c|}
\hline Enfermidades & $\begin{array}{c}\text { Registros } \\
\text { eclesiásticos (Livros } \\
\text { de óbitos) }\end{array}$ & $\%^{*}$ & $\begin{array}{c}\text { Inventários } \\
\text { post mortem }\end{array}$ & $\%^{*}$ \\
\hline Infectoparasíticas & 60 & 21,51 & 50 & 2,44 \\
\hline Sistema circulatório & 31 & 11,11 & 12 & 0,58 \\
\hline Sistema digestivo & 12 & 4,30 & 9 & 0,44 \\
\hline Sistema nervoso & 22 & 7,89 & 2 & 0,10 \\
\hline Sistema respiratório & 24 & 8,60 & 43 & 2,10 \\
\hline Osteomuscular & 4 & 1,44 & 51 & 2,48 \\
\hline Causas violentas/Defeitos diversos & 14 & 5,01 & 963 & 46,97 \\
\hline
\end{tabular}

Fonte: IPHAN, Vassouras, registros de óbitos de escravos e inventários post mortem, 1840-1880.

*Percentuais com base nos grupos de doenças.

Viana analisou as diferenças nas nomenclaturas sobre doenças e causas mortis nos inventários e nos registros eclesiásticos de óbitos. ${ }^{27}$ Nos registros eclesiásticos, as enfermidades infectoparasíticas eram as responsáveis pelo maior número de óbitos; enquanto nos registros dos inventários representavam apenas 2,44\% (50). As enfermidades do sistema respiratório são $8,60 \%$ nos livros óbitos e nos inventários somavam $2,10 \%$ do total. Vão se destacar as enfermidades associadas a "defeitos" e deficiências de um modo geral. A autora chama atenção de que tais "moléstias" relacionadas à visão, audição e mesmo invalidez alcançam índices de 46,97\%. Assim, quase metade dos escravizados nos inventários de Vassouras, entre 1840 e 1880, com algum problema de saúde, teve ou tinha problemas físicos gerados por moléstias ou acidentes. ${ }^{28}$

Os cafezais no Vale do Paraíba fluminense eram muitas vezes plantados em áreas escarpadas. Há várias iconografias de Victor Frond e também imagens de Ferrez com os cativos nas lavouras de café. Ali eram redistribuídos em grupos. Separados num sistema de trabalho por gangs ou turmas, denominado corte e beirada, os melhores cativos, provavelmente os mais jovens e robustos, eram escolhidos para ditar o ritmo da colheita. Quatro trabalhadores eram colocados na beirada dos cafezais, sendo o cortador e o contra-cortador de um lado e o beirador e o contra-beirador do outro. Dessa forma, os escravos mais velhos e lentos eram

27 VIANA, op. cit., p. 142-143.

28 Sobre morte de escravizados em Vassouras na segunda metade do século XIX, ver: REIS, Thiago de Souza dos. Morte e escravidão: padrões de morte da população escrava de Vassouras, 1865-1888. 2009. Dissertação (Mestrado em História) - Universidade Federal do Estado do Rio de Janeiro, Rio de Janeiro, 2009. 
colocados no meio. Muitas vezes, homens e mulheres trabalhavam na mesma turma. Os escravos colhiam em média cinco a sete alqueires diariamente. As formações ecológicas, ambientais e geografias nas áreas de Mata Atlântica e a formação da plantation cafeeira no primeiro quartel do século XIX também podiam impactar a saúde e adaptação da rotina de trabalho para os africanos. Podemos considerar assim as doenças e as enfermidades nos períodos de colheita.

\section{Olhares brancos sobre corpos negros}

NESSE COTIDIANO RURAL, e também no urbano, diferentes olhares incidiram sobre corpos africanos no séculoXIX, fossem eles escravizados, libertos ou livres, revelando dessemelhantes elementos. Viajantes, políticos, proprietários e médicos redigiram manuscritos, diários, matérias jornalísticas e manuais, apresentando sob a ótica peculiar do Outro - olhares europeus em relação à África, suas culturas e diversidade étnica -, múltiplos sentidos da escravidão. Contudo, perscrutavam, indagavam, descreviam, olhavam, mas, nem sempre viam. Adentrar nas senzalas não significava deter o privilégio do conhecimento sobre as vidas que ocupavam aquele espaço, bem como suas escolhas, amores, rancores, doenças, perspectivas e atitudes de africanos que, a partir da diáspora, tiveram que reconstruir seus mundos, seus laços familiares e suas identidades. As experiências atlânticas foram múltiplas e complexas, corroborando para ressignificações, mas também manutenções de saberes e de práticas.

Historicizar imagens e ideias sobre os corpos é fundamental nos processos de olhar e ver o passado, posto que, para cada sociedade, nos diferentes tempos, o corpo é pensado e definido seguindo pressupostos científicos, políticos e culturais. As descobertas da medicina apoiaram definições e percepções e, nesse sentido, como a ciência médica corroborou para construções e significados acerca do corpo africano - escravizado, liberto ou livre na sociedade escravista do Oitocentos? Para nossa análise utilizaremos o trabalho de dois médicos franceses que habitaram no Brasil na primeira metade do século XIX: Jean-Baptiste Alban Imbert e José Francisco Xavier Sigaud.

Jean-Baptiste Alban Imbert chegou ao Império do Brasil em 1831 e escreveu seu Manual do fazendeiro em momento político de muitas tensões: a primeira lei do fim do tráfico já havia sido promulgada e o tráfico tornara-se ilegal, mesmo estando a cultura cafeeira em expansão, ocupando lugar de destaque nas exportações do Império do Brasil. ${ }^{29}$ Suas lentes transcritas em seu manual nos permitem fazer emergir o pensamento, o olhar médico europeu e suas descrições sobre o africano e a África. Em sua perspectiva, a escravidão no Brasil, tendo o tráfico sido proibido, seria particularmente "mais doce e mais humana, pois que a

29 Sobre a relação entre a economia cafeeira e a mão de obra africana escravizada, ver: MARQUESE, op. cit.; MATTOS, Ilmar Rohloff de. O Tempo Saquarema. São Paulo: Hucitec, 2004; STEIN, Stanley. op. cit.; BARBOSA, op. cit., 2016. 
dificuldade de dar substituição ao que se possui fará recorrer aos meios os mais convenientes de conservar o que já se tem". ${ }^{30}$ Sua leitura acerca daquela sociedade não condizia com múltiplas realidades, incluindo informação do médico brasileiro David Jardim ao mensurar atitude de um proprietário em sua tese defendida na Faculdade de Medicina do Rio de Janeiro em 1847. Segundo Jardim, o proprietário, ao ser questionado sobre o modo de tratamento destinado aos seus escravizados e do risco de morte real, obteve como resposta ser a propriedade escravizada adquirida para utilização pelo período de um ano, no qual obteria o lucro desejado. Havendo óbito, compraria outros escravizados. Notemos que o proprietário menciona a compra de escravizados 16 anos após a primeira lei de fim de tráfico, portanto, referia-se ele à prática do comércio ilegal.

Conservar, pois, os escravizados, poderia significar modificação de padrões e de cuidados relativos à alimentação, vestimentas, trabalho, repouso e moléstias. $O$ isolamento no qual se encontravam muitos proprietários, cercados de "escravos indispensáveis ao trabalho de suas terras", os distanciava de tratamentos adequados a diferentes enfermidades que acometiam um grande número de almas. A distância de vilas e cidades, segundo Imbert, forçava proprietários e administradores de fazenda a exercerem a medicina, incluindo para tratar os negros, uma vez serem indispensáveis à subsistência das propriedades. E não só! Eram eles "muito mais susceptíveis de contrair moléstias que afligem a espécie humana", onerando produção e produzindo gastos com medicamentos e consultas médicas. Conjecturas que compartilhava com seus pares, brasileiros e estrangeiros.

Saberes sobre o corpo do trabalhador escravizado permitiriam maior controle da força de trabalho a ser explorada bem como determinar causas e tratamentos de enfermidades que, em muitos dos casos, produziam um número significativo de mortes, o que se tornara efetivamente preocupação a partir do fim do tráfico transatlântico em $1850 .{ }^{31}$ Os diferentes saberes e controle do corpo atendiam a pressupostos diferenciados, e o olhar de Imbert confere determinados motes expressos na atenção no momento da compra, da identificação da doença e seu tratamento, e, por último, a gravidez e o parto.

Imbert, apresenta o escopo inicial de seus estudos: a raça humana. Defende em seu manual a existência de duas delas: a branca e a negra, tendo sido esta última "colocada" na parte do mundo chamada africana. ${ }^{32} \mathrm{~A}$ partir desta definição emprega o termo negro para designar africanos em toda sua escrita. O escravizado, ainda segundo Imbert, teria vindo de uma "parte do mundo, onde a natureza pôs o berço da raça negra, aliás chamada Africana". ${ }^{33}$ Estando os negros "condenados a uma espécie de inferioridade, contraria as leis naturais, pede ao menos a justiça que não sobrecarreguemos muito o peso das cadeias, com que

30 IMBERT, J.B.A. Manual do fazendeiro ou tratado doméstico sobre as enfermidades dos negros. Typographia Nacional, 1839. Introdução, p. 12.

31 Sobre mortalidade escrava, ver: PEREIRA, Júlio Cesar Medeiros da Silva. À flor da terra: o cemitério dos pretos novos no Rio de Janeiro. Rio de Janeiro: Garamond; IPHAN, 2007.

32 IMBERT, J.B.A., op. cit., introdução, p. XXI.

33 Ibidem, introdução. 
o nosso orgulho Ihes agrilhoa os pulsos", deveriam os senhores, antes, diminuir o máximo possível o peso da escravidão. Acreditava assim "que esta raça há de então melhorar tanto em seus princípios e costumes como no seu estado físico". ${ }^{34}$ A relação entre território, raça e inferioridade, na perspectiva de Imbert, poderia, por meio de uma escravização menos pesada, possibilitar aprimoramento moral, de costumes e estado físico aos africanos.

Se Imbert simplifica a classificação humana em negra e branca, José Francisco Xavier Sigaud apresenta outra perspectiva acerca do termo raça. Inicialmente, para este médico, havia três raças, o que foi alterado a partir da miscigenação: "a existência sobre o mesmo solo de três raças distintas - branca, vermelha e negra" - possibilitou, "por cruzamento, a uma quarta raça mestiça". O que, para o médico, necessitava da atenção de zoologistas "no sentido de tentarem solucionar uma série de questões importantes, como a degeneração da raça branca, a extinção da raça vermelha, a multiplicação da raça negra e a fecundação da raça mestiça". ${ }^{35}$ Embora aponte a existência de quatro raças, se detém sobre os indígenas e sua pluralidade étnica.

Imbert, objetivando organizar ofícios, divide os escravizados em "quatro classes" segundo suas idades: "compreende a $1^{\mathrm{a}}$ os de 10 até 18 anos de idade; a $2^{\mathrm{a}}$ os de 18 até 35 ; a $3^{\mathrm{a}}$ os de 35 até 55 ; e a $4^{\mathrm{a}}$ os de 55 para cima". Deveria, ainda segundo o médico, ressaltar a especialidade destinada a cada uma das classes, notando "as forças, a inteligência e a experiência próprias destas diferentes épocas da vida". ${ }^{36}$ A divisão em classes permitiria ao médico identificar suas habilidades e forças específicas para cada faixa etária. E, para o senhor, alocar os diferentes grupos em ofícios específicos, pressupondo, assim, alcance do melhor proveito em benefício da produção de sua fazenda.

\section{Considerações finais}

PARA ALÉM DA MORTALIDADE produzida pelo tráfico atlântico é necessário conhecer os padrões das doenças dos africanos nos mundos do trabalho. Em diferentes contextos, africanos tiveram que ser adaptados a climas, regime de trabalho, práticas agrícolas e uso de ferramentas. Mesmo considerando os impactos do tráfico atlântico, houve experiências africanas de adaptação física aos diversos tipos trabalho. É fundamental considerar os contextos climáticos, ecológicos, agrícolas, geográficos, cultura material, ferramentas, alimentação e atividades de rotina, considerando assim impactos sobre os corpos e mentes dos africanos.

Registros de enfermidades, doenças e causas mortis vão aparecer de diferentes formas nas fontes disponíveis, incidindo sobre padrões da mortalidade e variáveis das sociabilidades e relações de produção e trabalho. Novas pesquisas podem demonstrar tanto diferentes impactos microbianos como aqueles produzidos por doenças associadas exclusivamente às

34 Ibidem, título VI, cap. XVII, p. 259-260.

35 SIGAUD, op. cit., p. 302.

36 IMBERT, J.B.A., op. cit., cap. XL, p. 357-358. 
condições físicas dos regimes de trabalho em conjunturas demográficas. Diante de aspectos ambientais, organização do trabalho e dieta alimentar, vamos encontrar diferentes reflexos em torno da morbidade dos trabalhadores nas áreas escravistas.

Diferentes fontes, com naturezas diversas, podem nos aproximar das condições de saúde e vida dos trabalhadores escravizados. O que representava a vida diária dos trabalhadores escravizados em áreas de produção de algodão, arroz, café, cana e outras? Podemos refletir sobre os impactos dessas rotinas de trabalho, incluindo as enfermidades provocadas no corpo dos escravizados, associando a disfunções musculares e ortopédicas em determinados contextos da vida escrava. Consideramos que parte das enfermidades dos cativos africanos estava não só associada às epidemias e às dietas alimentares, mas também ao trabalho realizado.

Recebido em: 29/06/2020

Aceito em: 04/08/2020 